\title{
Review Essays
}

\section{In Search of Young Citizens}

\author{
Yatun Sastramidjaja \\ University of Amsterdam \\ Y.Sastramidjaja@uva.nl
}

Kathryn Robinson (ed.), Youth Identities and Social Transformations in Modern Indonesia. Leiden; Boston, MA: Brill, 2015, xvi + 288 pp. ISBN 9789004290464, price: USD 97.00 (hardback).

Doreen Lee, Activist Archives. Youth Culture and the Political Past in Indonesia. Durham; London: Duke University Press, 2016, xviii +278 pp. ISBN 9780822361527, price: USD 89.95 (hardback); 9780822361718, 24.95 (paperback).

The 2009 Law of Youth in Indonesia defines 'youth' ( pemuda) — a category that previously lacked clear legal definition - as 'Indonesian citizens who are entering an important period of growth and development and are aged between 16 and 30 years'. This includes 26.6 per cent of the population, or 62.3 million 'youth', according to the 2010 census, and their numbers have most likely increased since. But who are these young citizens, and what kind of growth and development does this definition entail? In Indonesian developmentalist discourse, a New Order legacy, youth represent the budding flower of the nation whose growth requires proper nurturing and guidance for them to become the building blocks of national development, or -in the globalist discourse increasingly adopted by Indonesian officials—-for youth to realize their potential as 'quality human resources'. The concept of youth thus signifies the transition from childhood dependency to productive citizenship, which makes youth important, mainly, as the future drivers of Indonesia's economic growth and global competitiveness. However, this teleological framing obscures how

(C) YATUN SASTRAMIDJAJA, 2017 | DOI: 10.1163/22134379-17304003

This is an open access article distributed under the terms of the prevailing CC-BY-NC license 
youth not only become but already are young citizens, who practice citizenship according to their own moral valuations, concerns, and aspirations that are firmly rooted in their lived experiences of the conditions they find themselves in.

The relevance of studying youth on their own terms is demonstrated in the books under review in this essay. Kathryn Robinson's volume on everyday youth identities and Doreen Lee's ethnography of activist youth are excellent contributions to the growing scholarship in Indonesian youth studies, which they help to consolidate as an important field of research in its own right. Both books offer fascinating, in-depth portrayals of youth as real actors in their own stories of life. However, in focusing on the seemingly separate realms of the 'ordinary' and the 'political', they offer very different analyses, stressing different temporal orientations. While Robinson's volume frames the lives of 'ordinary youth' in terms of future aspirations, set in a context of incremental social change, Lee links the politicized lives of activist youth to rousing constructs of the past, set in a context of political upheaval as well as stagnation. Yet, both also attempt to bridge the ordinary and the political—or rather, to identify the political in the ordinary, and vice versa - by highlighting the micropolitics of the cultural practices of the youth at issue. In so doing, both works produce novel insights that suggest promising directions for the study of youth in Indonesia, which is especially urgent for a critical reappraisal of the meaning of youth citizenship. Still, more focused theorizing is needed for this to develop into solid new research agendas.

Youth Identities and Social Transformations certainly offers a rich and varied look into the meaning of being young in contemporary Indonesia. With contributions from two major research projects - the Australian 'Ambivalent Adolescents in Indonesia' and the Dutch 'In Search of Middle Indonesia' - the volume includes ten case studies of urban and rural youth across the country (although Java is most heavily represented), preceded by two chapters on 'the big picture' of studying youth in Indonesia. In his theoretical chapter, Ben White sets the tone by critically unpacking notions of 'youth' and 'generation' as social constructs that carry weighty moral, political, and economic connotations, arguing that 'the sometimes wide gap between construction and experience is one key to understanding young people's lives' (p. 4). Hence a recurring theme in the volume is how young people respond to dominant discourses about them in Indonesia, which typically depict youth as either 'agents of change' or 'moral hazards'. However, this twin notion of the promise and perils of youth is nothing new but was at the core of official youth policy during the New Order, when idealizing as well as damning representations of youth were systematically deployed for political purposes. This begs the question what dif- 
ference the context of democratization has made to the politics of youth in Indonesia. If the volume were written twenty years ago, would it look much different?

A hint of an answer is provided in White's apposite remark that the extended definition of youth to the age of 30 , since 2009, 'risks juvenilizing young adults as something less than full members of society, less than full citizens', and given the lack of a sociological basis he suggests that 'the main basis for the extended definition is political' (p. 7). Regrettably, he does not elaborate on this point. Yet the notion of a 'deficient citizenship' offers critical clues for a more substantial understanding of youth citizenship as a social condition that is indeed inherently political. For one thing, the prolongation of youth as 'less than full citizens' fits the conditions of socioeconomic precarity which the neoliberal policies of post-New Order governments have reinforced. As comparative literature shows, growing precarity condemns young people across the globeespecially those groomed for 'quality' productive citizenship - to an indefinite state of waiting. This breeds anxiety over uncertain futures and unsettled lives, but it also creates a realm of possibility for giving alternative substance to citizenship. This is the realm of youth agency which the volume highlights as young people's contribution to social transformation.

This agency is made evident, above all, in young people's personal ambition and effort. As Pam Nilan, Lyn Parker, Kathryn Robinson, and Linda Bennett show in their discussion of youth's future aspirations, based on a national survey conducted in 2007 and 2008, youth are strikingly optimistic as they equip themselves to the best of their abilities for future careers through educational achievement, despite being well aware of the precarious labor market that awaits them after graduation. A sense of personal drive also speaks from Robinson's chapter on youth aspirations in an industrial town in South Sulawesi, where the prospect of landing well-paying jobs in the town's mining company prompts many youth to sojourn in cities elsewhere to obtain the best possible education, fully supported by their parents who trust that their children will value this opportunity given to them. With the government's development agenda, the company's interests, and youth as well as parental ambitions thus converging in the trope of 'quality human resources' (p. 74), productive citizenship seems an attainable dream worth chasing. In other settings, though, such as the Javanese village studied by Ben White and C. Ugik Margiyatin, dire job prospects create an acute sense of waiting. Here, too, youth pursue personal ambitions through extended schooling; but to them, rather than a sure path to desirable careers, the educational realm is especially valued for providing a space for peer interactions that gravitate towards modern lifestyles, offering relief from the personal restrictions of village life. 
The tension between restrictions and expanded lifeworlds is another recurring theme. As Patrick Guinness shows with regard to Yogyakarta, youth seek 'to forge a new place for themselves' (p. 137) in the modern city—away from the 'kampong societies of their parents' that 'no longer satisfy [their] aspirations' (p. 151) - but to the parental generation the liberal behaviors that accompany their expanded horizons seem to pose a moral threat. Moralizing discourses, however, seem to be losing their disciplinary effect. Tracy Wright Webster shows that young women in Yogyakarta flatly reject 'moral panics' around liberal behaviors as an infringement on private choice, which makes them 'agents in the process of cultural change', embodying 'new forms of resistance to societal norms' (pp. 235-236). Yet, agency is not only resistance. As Lyn Parker and Pam Nilan show with regard to teenage girls in Minangkabau and Solo, youth also exert agency in adhering to social norms, and contrary to popular fears, peer interactions are crucial in that. More so than parents, Parker points out, peers act as 'an external conscience' to protect each other's propriety in everyday situations, taking pride in their ability to navigate morality and modernity and make the 'right choices' together. Nilan further shows how youth manage mixed-sex socializing through 'judicious control over time and space' (p. 157), knowing that internet cafés must be avoided at $9 \mathrm{pm}$, but at $3 \mathrm{pm}$ form perfectly safe spaces for mild flirtations, 'made possible by technologically-mediated interaction and the reassuring ambience of the friendship group' (p. 164). Peer groups thus enable youth autonomy, which is vital to developing a sense of civic worth. Conversely, as Linda Bennett shows for the case of teenage mothers in Lombok, being deprived of a peer group following marriage and motherhood also entails a loss of social freedom.

Finally, the theme of agency through group identification is highlighted in Patricia Spyer's elegant photo-essay on the creative outbursts of 'streetwise masculinity' in post-conflict Ambon, Noorhaidi Hassan's instructive discussion of the heroic identity offered by Islamist movements, and Pujo Semedi's engaging ethnography of the scouting movement. Each of these collectivities represents alternative modes of citizenship. Even the scouting movement, which remains tied to government regulations and patriotic moral codes, provides a relatively autonomous and playful realm for overcoming 'deficient' citizenship. As Semedi puts it, through the active participation required in scouting young people learn 'to be not merely passengers but crew and officers in the ship of life' (p. 127). In a context where, as White and Margiyatin note, the rhetoric of 'young people's participation rights and active citizenship ... remain largely "omong kosong" (empty words)' (p. 67), this prospect seems attractive indeed. It is why young people continue to flock to all sorts of movements and collectivities where participation becomes real. 
In Indonesia, the quintessential vehicle for youth participation is the student movement. However, as noted above, this is seen to belong to a 'political' realm which is separated from the 'ordinary' realm of youth. Thus, the 2009 Law of Youth, in a supplement, highlights the historic feats of student movements in Indonesia as evidence of the 'vanguard' role of youth, yet without mentioning student activism (rather than educational or social student activities) among the proper types of youth participation. Besides the evidently political reasons for this omission-i.e., the fact that student movements attack the government-it confirms White's contention that the legal definition reduces youth to 'less than full citizens', unqualified for political involvement. This further implies that, in contrast, student activists are somehow 'more than not-yet citizens', indeed that student movements represent something different altogether from both categories of 'youth' and 'citizenship'. That this separation is mistaken is demonstrated in Doreen Lee's book.

The first real ethnography of student activism in Indonesia, Activist Archives brilliantly describes how student activists constantly move between the 'ordinary' and the 'political' dimensions of their lifeworld, showing that these are in fact intertwined in what Lee identifies as the 'material and ideational spaces' of student activism. In six chapters titled after these 'spaces' - 'Archive', 'Street', 'Style', 'Violence', 'Home', and 'Democracy' - Lee offers a unique look into the social life behind the distinctive signs and symbols of student activism; from activist documentation, to street demonstrations with the ubiquitous protest T-shirts and frequent violent encounters, and from the intimacy of activist dwellings to the treacherous political arena. While these spaces and symbols do set student activism apart from any other type of youth practice, Lee reveals how 'ordinary' youth culture and youthfulness permeate the culture of student activism, as well as vice versa. Since the era of reform, regular youth trends have eagerly picked up on the visual culture of student protest, which has 'extended the domain of politics into the realm of public culture'; and thereby, Lee argues, 'the student activists of 1998 created a new model of citizenship for Indonesian youth by making political participation desirable and accessible' (p. 91).

Neither Lee's book nor Robinson's volume further examine what such new models of youth citizenship might look like or entail. Yet this is deeply relevant to the ongoing process of democratization, all the more given current conflicts over the very meaning of citizenship in Indonesia. Together, though, the two books offer a great wealth of significant insights that should spur new research agendas that take youth citizenship seriously. 